\title{
análise Comparativa do Potencial Alelopático do Extrato hidroalcoólico e do Óleo Essencial de folhas de Cipó-D'alho (BIGNONIACEAE) ${ }^{1}$
}

\author{
Comparative Analyses of the Allelopathic Potential of the Hydroalcoholic Extract and Essential \\ Oil of "Cipo-D'alho" (Bignoniaceae) Leaves
}

\author{
SOUZA FILHO, A.P.S. ${ }^{2}$, GUILHON, G.M.S.P. ${ }^{3}$, ZOGHBI, M.G.B. ${ }^{4}$ e CUNHA, R.L. ${ }^{5}$
}

\begin{abstract}
RESUMO - A alelopatia é um importante mecanismo que influencia a estabilidade de agroecossistemas. A identificação desse caráter, em muitos casos, realiza-se via análise dos efeitos de extratos brutos polares. No presente trabalho, caracterizou-se a atividade alelopática do cipó-d'alho (Mansoa standleyi - Bignoniaceae), analisando-se, comparativamente, o extrato hidroalcoólico e o óleo essencial das folhas da planta, procurando-se estabelecer a necessidade de se considerar, em estudos dessa natureza, a abordagem envolvendo extratos apolares. Realizaram-se bioensaios de germinação e desenvolvimento da radícula e do hipocótilo de malícia (Mimosa pudica), em períodos de dez dias, empregando-se concentrações de 0,5\%, $1,0 \%$ e 2,0\%. Foram identificados, ainda, os principais constituintes químicos do óleo essencial. Os resultados indicaram que tanto o extrato hidroalcoólico como o óleo essencial apresentaram potencial para inibir a germinação e o desenvolvimento da radícula e do hipocótilo. O extrato hidroalcoólico manifestou maior potencial inibitório sobre a germinação, enquanto o óleo essencial promoveu inibições mais expressivas sobre o desenvolvimento da radícula e do hipocótilo. Os efeitos estiveram positivamente associados à concentração, com efeitos máximos e minimos obtidos nas concentrações de $2,0 \%$ e $0,5 \%$, respectivamente. Compostos sulfurados, como o dissulfeto de dialila $(42,15 \%)$ e o trissulfeto de dialila $(11,25 \%)$, isoladamente ou em associação, estão envolvidos nos efeitos alelopáticos promovidos pelo óleo essencial. Adicionalmente, os resultados obtidos apontam para a necessidade de se considerar a utilização de extratos apolares quando da análise da atividade alelopática de uma dada planta, especialmente se não houver informações sobre a produção de óleo essencial pela planta prospectada.
\end{abstract}

Palavras-chave: alelopatia, compostos polares, compostos apolares, inibição.

ABSTRACT - Allelopathy is an important mechanism that affects the stability of agro-eco systems. The identification of this character, in several cases, is accomplished via analysis of the effects of polar crude extracts. The allelopathic activity of the species "cipó-de-alho"(Mansoa standleyi Bignoniaceae) is characterized in the present work, by comparing the effects of the hydroalcoholic extract and essential oil of the leaves, attempting to establish the need to consider in research of this nature the approach involving non polar extracts. Bioassays of the weed plant 'malicia" (Mimosa pudica) radicle and hypocotyl germination and growth were carried out in periods of 10 days, using concentrations of $0.5 \% ; 1.0 \%$ and $2.0 \%$. The chemical constituents of the essential oil were also identified. The results showed that both the hydroalcoholic extract and the essential oil have the potential to inhibit radicle and hypocotyl germination and growth. The hydroalcoholic extract showed higher potential to inhibit germination, while the essential oil promoted more intense inhibitions on radicle and hypocotyl growth. The effects were positively related with concentration, with maximum and minimum effects being obtained at concentrations of $2.0 \%$ and $0.5 \%$, respectively. The sulfur compounds diallyl disulfide (42.15) and diallyl trisulfide (11.25\%), alone or in association, are involved with the allelophatic effects caused by the essential oil. In addition, the results point to the need to consider using non polar extracts when evaluating the allelopathic activity of a given plant, especially when there is no information about the production of essential oil by the prospected plant.

Keywords: allelopathy, polar compounds, non polar compounds, inhibition.

Recebido para publicação em 12.12.2008 e na forma revisada em 13.11.2009.

Engo-Agro.., Dr., Embrapa Amazônia Oriental, Trav. Dr. Enéas Pinheiro, S/N, 66095-100 Belém-Pará, <apedro@cpatu.embrapa.br;

${ }^{3}$ Quím. Dra., Universidade Federal do Pará. Rua Augusto Corrêa 01, 66075-900 Belém-Pará, <giselle@ufpa.br>; ${ }^{4}$ Engenheira Química, Dra., Museu Paraense Emílio Goeldi, Caixa Postal 399. 66040-170 Belém-Pará, <zoghbi@museu-goeldi.br>; ${ }^{5}$ Biólogo, Dr., Embrapa Amazônia Oriental, <rlisboa@cpatu.embrapa.br>. 


\section{INTRODUÇÃO}

A alelopatia, efeito direto e/ou indireto de determinada planta sobre outras em sua vizinhança, via produção e liberação de substâncias químicas para o ambiente, é considerada um fenômeno de larga ocorrência em comunidades de plantas tanto nativas como cultivadas; é postulado como mecanismo importante a ditar variações na dinâmica da população de plantas, sendo responsável por alterações expressivas na densidade, na diversidade e no desempenho das espécies, o que redunda em alterações na sustentabilidade dos agrossistemas (Khanh et al., 2005). Nesse contexto, a identificação de atividade alelopática em espécies de plantas, cultivadas ou nativas, assume papel relevante na interpretação do papel ecológico que elas desempenham em suas comunidades, mormente em relação ao seu potencial para controlar espécies de plantas daninhas, considerado um dos principais problemas limitantes ao desenvolvimento da atividade agrícola nas regiões tropicais.

Em razão dessas especificidades biológicas, nas últimas seis décadas, vários trabalhos de pesquisa foram desenvolvidos no mundo, com vista a identificar espécies de plantas com potencial para fornecer moléculas químicas com propriedades relevantes aos interesses da agricultura, sobretudo em relação à produção de bioerbicidas (Duke et al., 2002; Anaya et al., 2003, 2005; Heisey \& Heisey, 2003). Os protocolos empregados, em fase inicial das pesquisas, envolve a utilização de diferentes frações da planta ou até mesmo da planta inteira, com extrações com eluentes de alta polaridade - como são os casos do metanol e da água - isoladamente ou em mistura com diferentes proporções, em concentrações fixas ou variadas. Os trabalhos de Gatti et al. (2004), Ismail \& Chong (2002), Turk et al. (2003) e Sobrero et al. (2004) são bons exemplos desses procedimentos. A hipótese considerada, nesses casos, é a de que as substâncias presentes nos extratos expressam o potencial da atividade alelopática da planta prospectada, o que apontaria para a necessidade ou não de estudos subsequentes, com vista ao isolamento e à identificação dos compostos químicos envolvidos na atividade alelopática.
Os resultados desses esforços são expressivos e, de maneira contundente, propiciaram a identificação e seleção de várias espécies de plantas com potencial de uso direto ou como fornecedor potencial de novas moléculas químicas com perspectiva de uso, em formulações inovadoras, em diferentes atividades agrícolas. Exemplos positivos desses aspectos podem ser observados em diferentes trabalhos disponíveis na literatura, como os de D'Abrosca et al. (2005), Kato-Noguchi (2003) e Chon \& Kim (2002).

Em passando recente, investigações sobre a importância dos óleos essenciais na atividade biológica das plantas mereceram especial atenção por parte dos pesquisadores da área de ecologia química. Em muitos trabalhos, foram relatados efeitos inibitórios potentes tanto da germinação de sementes como do desenvolvimento de diferentes espécies de plantas (Isman, 2000; Barney et al., 2005; Kong et al., 2005; Nishida et al., 2005). Esses resultados são indicativos claros de que altas polaridades nem sempre revelam as reais potencialidades de uma espécie de planta e apontam, ainda, para a necessidade de abordagem mais ampla em estudos de prospecção inicial de plantas, com vista à identificação de atividade alelopática relacionada à presença de compostos químicos de baixa polaridade, o que implica a utilização de solventes como hexano e éter etílico ou então testar os óleos essenciais dessas plantas em bioensaios apropriados. Dessa forma, neste trabalho, caracterizou-se a atividade alelopática do cipód'alho (Mansoa standleyi), analisando-se, comparativamente, extratos com substâncias de alta polaridade e o óleo essencial da referida planta.

\section{MATERIAL E MÉTODOS}

Coleta do material botânico: folhas de cipód'alho (Mansoa standleyi (Steyerm.) A.H. Gentry - Bignoniaceae) foram colhidas no campo experimental de plantas medicinais da Embrapa Amazônia Oriental, localizado em Belém, PA. Uma exsicata encontra-se depositada no herbário do Museu Paraense Emílio Goeldi (MG 188.707). O material passou por processo de secagem em estufa de circulação forçada de ar, a $40{ }^{\circ} \mathrm{C}$ de temperatura constante, 
por 72 horas, e, em seguida, foi triturado em moinho tipo Willey, mantido em condições ambientais e embalado em sacos de plástico. O processo permitiu a obtenção de $3,4 \mathrm{~kg}$ de material seco e triturado.

Preparo do extrato hidroalcoólico: o material seco e triturado foi submetido à extração exaustiva com solução hidroalcoólica $(7: 3$ metanol: água), sucessivamente, envolvendo 4,0 litros da solução para cada kg de material seco, por um período de oito dias. A parte alcoólica da mistura foi separada da fração aquosa em rotavapor tipo EL 131. Em seguida, a fração aquosa foi liofilizada e armazenada em potes de vidro, em condições ambientais normais, sem controle de temperatura e umidade relativa do ar.

Tanto o extrato hidroalcoólico como o óleo essencial foram testados nas concentrações de $0,5,1,0$ e 2,0\%. Especificamente para o extrato hidroalcoólico, utilizou-se o material liofilizado. Como eluente, foi empregada, no preparo do extrato hidroalcoólico, solução hidroalcoólica (metanol: água) na mesma proporção daquela utilizada na extração do óleo essencial, éter etílico. Stowe (1979) estabelece a concentração de $5,0 \%$ como limite para estudos dessa natureza. No presente trabalho, a concentração máxima empregada foi de $2,0 \%$, bem abaixo da apresentada.

Obtenção e identificação dos componentes químicos do óleo essencial: folhas de cipód'alho foram obtidas da mesma planta e na mesma ocasião, de onde se coletou material botânico para obtenção do extrato hidroalcoólico. O material permaneceu em condições ambientes até que apresentasse consistência quebradiça. A extração do óleo foi realizada por arraste, em extrator Clevenger, por quatro horas consecutivas. Após essa fase, quantidades de sulfato de sódio anidro foram adicionadas ao destilado, para secagem mais eficiente.

Os principais componentes do óleo essencial foram identificados via cromatografia gasosa (CG/MS), em sistema Shimadzu QP-2010 Plus equipado com coluna Rtx-5MS (30 m x 0,25 mm; 0,25 mm de espessura de filme); o gás de arraste foi o hélio, em velocidade linear de $50 \mathrm{~cm} \mathrm{~s}^{-1}$ (pressão $75,5 \mathrm{Kpa}$ ), com injeção sem divisão de fluxo de $2 \mu \mathrm{L}$ de uma solução de $2 \mu \mathrm{L}$ do óleo, em 1,0 mL de hexano; temperatura do injetor de $250{ }^{\circ} \mathrm{C}$; programa de temperatura: $60{ }^{\circ} \mathrm{C}-240{ }^{\circ} \mathrm{C}\left(3^{\circ} \mathrm{C} /\right.$ min); EM: impacto eletrônico, $70 \mathrm{eV}$; e temperatura da fonte de íns e partes de conexão: $180{ }^{\circ} \mathrm{C}$. A identificação foi por comparação dos espectros de massas e indices de retenção (IR), com os sistemas na biblioteca NIST-05 e da literatura (Adams, 2007). A quantificação foi obtida por CG, equipado com detector de ionização de chama (DIC), nas mesmas condições operacionais, exceto o gás de arraste, que foi o hidrogênio. A porcentagem da composição foi obtida pela área dos picos, sem uso de fator de resposta.

Planta receptora: utilizou-se como planta indicadora a planta daninha malícia (Mimosa pudica). As sementes, coletadas em fazendas particulares, no município de Castanhal, Pará, passaram por processo de limpeza e foram tratadas para superação da dormência, pela imersão em ácido sulfúrico concentrado, conforme estabelecido por Souza Filho et al. (1998).

Bioensaios de germinação: a germinação foi monitorada em períodos de dez dias, em condições de temperatura constante de $25{ }^{\circ} \mathrm{C}$ e fotoperíodo de 12 horas, envolvendo contagens diárias e eliminação das sementes germinadas. Cada placa de Petri, de 9,0 cm de diâmetro, forrada com uma folha de papel-filtro qualitativo, recebeu 25 sementes.

Bioensaios de desenvolvimento da radicula e do hipocótilo: foram realizados em condições de temperatura constante de $25{ }^{\circ} \mathrm{C}$ e fotoperíodo de 24 horas. Para cada placa de Petri de $9,0 \mathrm{~cm}$ de diâmetro, forrada com uma folha de papel-filtro qualitativo, adicionaram-se três sementes pré-germinadas por aproximadamente três dias. Após dez dias de crescimento, mediu-se o comprimento da radícula e do hipocótilo.

Outros procedimentos: em todos os bioensaios, cada placa de Petri recebeu o volume de 3,0 mL do extrato e de água; no caso do tratamento testemunha, o extrato e o óleo essencial foram adicionados apenas uma vez, quando do início do experimento, sendo, a partir de então, adicionada apenas água destilada, sempre que necessário. Quando da adição do extrato e do óleo, deixou-se evaporar a fase alcoólica, adicionando, em seguida, 
água destilada na quantidade evaporada, mantendo-se, dessa forma, a concentração original.

\section{Análise estatística}

O delineamento experimental, para todos os bioensaios, foi inteiramente casualizado, em modelo hierárquico, com dois fatores e quatro repetições. Procedeu-se à análise de variância dos dados obtidos pelo teste $\mathrm{F}$, e as médias foram comparadas pelo teste de Tukey (5\%). Os dados foram analisados pelo programa estatístico SAS (SAS, 1989). Em todas as comparações utilizou-se, como tratamento testemunha, a água destilada. Os dados foram transformados para arc. sen. $\sqrt{ } \mathrm{x}$.

\section{RESULTADOS E DISCUSSÃO}

Em estudos em que se pretende avaliar a atividade alelopática de extratos brutos, em condições de laboratório, um ponto importante a ser considerado é aquele referente a efeitos que podem levar a superdimensionar a atividade do que se está avaliando. Entre os fatores que podem contribuir para essa supervalorização, merece destaque a contribuição do potencial osmótico dos extratos - esse aspecto assume maior importância à medida que as concentrações são mais elevadas. Dessa forma, para obter as reais potencialidades da atividade alelopática, faz-se necessário descontar os efeitos do potencial osmótico para determinadas concentrações. No presente trabalho, a concentração máxima testada foi de 2,0\%; para concentrações até esse valor, a contribuição do potencial osmótico deve ser desprezada, conforme Souza Filho \& Alves (2000). Assim, os efeitos encontrados podem ser atribuídos, exclusivamente, à atividade dos constituintes químicos presentes no extrato hidroalcoólico e no óleo essencial.

A intensidade dos efeitos potencialmente alelopáticos sobre a germinação das sementes da planta daninha malícia foi dependente tanto do extrato utilizado como da concentração (Tabela 1). Comparativamente, o extrato hidroalcoólico apresentou inibições superiores, estatisticamente $(\mathrm{p}<0,05)$, àquelas do óleo essencial, para todas as concentrações. Quanto ao extrato hidroalcoólico, a inibição máxima foi atingida na concentração de $1,0 \%$, não havendo diferença $(p>0,05)$ entre esta concentração e a de $2,0 \%$, (para os dados originais, a inibição nessa concentração foi de 100\%), enquanto para o óleo essencial a inibição máxima foi de $52,1 \%$, na concentração de $2,0 \%$. Esses resultados indicam que as substâncias de alta polaridade encontradas no extrato hidroalcoólico do cipó-d'alho possuem maior potencial inibitório da germinação de sementes do que aquelas de baixa polaridade presentes no óleo essencial.

Os efeitos promovidos pelo extrato hidroalcoólico sobre a germinação das sementes são de magnitude superior àquela efetivada, para a mesma espécie de planta receptora e concentrações equivalentes, pelo extrato bruto de folhas do feijão-de-porco (Canavalia ensiformis), de casca e folhas do acapu (Vouacapoua americana) e de folhas de capimsalsar (Cymbopogon sp.) (Souza Filho, 2002; Dias \& Souza Filho, 2005). Contudo, a atividade inibitória verificada para o óleo essencial de outras espécies de plantas apontam para intensidade superior às obtidas no presente trabalho, como se pode verificar nos resultados de Souto et al. (1995) e Kohli \& Singh (1991).

As inibições efetivadas sobre o desenvolvimento da radícula (Tabela 2) e do hipocótilo (Tabela 3) foram de menor intensidade que as verificadas sobre a germinação das sementes, especialmente em relação às promovidas pelo extrato hidroalcoólico. À semelhança do observado no bioensaio de germinação, os efeitos estiveram positivamente associados ao aumento da concentração, com inibições máxima

Tabela 1 - Efeitos potencialmente alelopáticos de diferentes concentrações do extrato hidroalcoólico e do óleo essencial de folhas de cipó-d'alho (M. standleyi) sobre a germinação de sementes de malícia (M. pudica). Dados expressos em percentual de inibição em relação ao tratamento testemunha (água destilada)

\begin{tabular}{|c|c|c|}
\hline \multirow{2}{*}{ Concentração (\%) } & \multicolumn{2}{|c|}{ Solução-teste } \\
\cline { 2 - 3 } & Extrato hidroalcoólico & Óleo essencial \\
\hline 0,5 & $47,3(0,33) \mathrm{Ba}$ & $26,3(0,24) \mathrm{Cb}$ \\
\hline 1,0 & $90,0(0,0) \mathrm{Aa}$ & $39,2(0,33) \mathrm{Bb}$ \\
\hline 2,0 & $90,0(0,0) \mathrm{Aa}$ & $52,1(0,19) \mathrm{Ab}$ \\
\hline
\end{tabular}

Médias seguidas de letras iguais, maiúsculas na coluna e minúsculas na linha, não diferem pelo teste de Tukey (5\%). 
e mínima verificadas nas concentrações de 2,0 e $0,5 \%$, respectivamente. Ao contrário do observado no bioensaio de germinação, o óleo essencial apresentou maior potencial para inibir o desenvolvimento tanto da radícula como do hipocótilo.

Considerando a inibição mínima de 50\% como um padrão satisfatório para avaliar as potencialidades alelopáticas de um extrato (Dudai et al., 1999), observa-se que, para o extrato hidroalcoólico, esse valor foi atingido a partir da concentração de $1,0 \%$, em relação à germinação de sementes. Para os efeitos sobre o desenvolvimento da radícula (Tabela 2) e do hipocótilo (Tabela 3), as inibições estiveram bem abaixo desse valor. Quanto aos efeitos efetivados pelo óleo essencial, inibições dessa ordem foram verificadas sobre a germinação de sementes e o desenvolvimento do hipocótilo, na concentração de 2,0\%. Esses dados revelam o grande potencial que as folhas do cipó-d'alho têm como fonte de agentes químicos com potencial alelopático, quer em relação aos compostos químicos presentes no extrato hidroalcoólico, quer em relação aos constituintes químicos do óleo essencial.

A atividade biológica de um dado aleloquímico depende tanto da concentração como do limite da resposta da espécie afetada. O limite da inibição para determinada substância não é constante, porém está intimamente relacionado à suscetibilidade da espécie receptora. A resposta de uma dada planta à presença de químicos pode ser tanto inibitória como estimulativa (An et al., 1993), cabendo à concentração papel decisivo nas respostas encontradas (Rice, 1984). No presente trabalho,

Tabela 2 - Efeitos potencialmente alelopáticos de diferentes concentrações do extrato hidroalcoólico e do óleo essencial de folhas de cipó-d'alho (M. standleyi) sobre o desenvolvimento da radícula de malícia (M. pudica). Dados expressos em percentual de inibição em relação ao tratamento testemunha (água destilada)

\begin{tabular}{|c|c|c|}
\hline \multirow{2}{*}{ Concentração (\%) } & \multicolumn{2}{|c|}{ Solução-teste } \\
\cline { 2 - 3 } & Extrato hidroalcoólico & Óleo essencial \\
\hline 0,5 & $4,6(0,41) \mathrm{Cb}$ & $19,7(0,29) \mathrm{Ca}$ \\
\hline 1,0 & $28,7(0,39) \mathrm{Bb}$ & $33,4(0,54) \mathrm{Ba}$ \\
\hline 2,0 & $36,3(0,34) \mathrm{Ab}$ & $41,6(0,33) \mathrm{Aa}$ \\
\hline
\end{tabular}

Médias seguidas de letras iguais, maiúsculas na coluna e minúsculas na linha, não diferem pelo teste de Tukey (5\%). efeitos positivamente associados à concentração foram observados em todos os bioensaios. A concentração minima estabelecida de $0,5 \%$ aparentemente esteve acima daquela exigida para efetivar efeitos estimulativos tanto sobre a germinação das sementes quanto sobre o desenvolvimento da radícula e do hipocótilo, embora efeitos de baixa magnitude, promovidos pelo extrato hidroalcoólico, tenham sido detectados sobre o desenvolvimento da radícula da espécie malícia, na concentração de $0,5 \%$ (Tabela 2).

Os efeitos de extratos brutos e de óleos essenciais sobre a germinação de sementes e o desenvolvimento de plântulas são frequentemente explicados em termos individuais de alguns dos principais constituintes ou mesmo de determinadas classes químicas presentes. Entretanto, tanto o óleo essencial como os extratos brutos são mistura de diferentes componentes em proporções variadas e é frequentemente desconhecido se e como esses constituintes interagem entre si e promovem seus efeitos sobre outros organismos. Paralelamente, há considerável variação na composição dos constituintes de extratos brutos e de óleos essenciais entre espécies de plantas; essa variação pode ocorrer em função tanto da sazonalidade como da diferença entre indivíduos de diferentes populações e indivíduos de mesma população (Tarayre et al., 1995; Kokkini \& Vokou, 1989). Esses aspectos implicam maior ou menor atividade alelopática. Para extratos hidroalcoólicos, altas atividades inibitórias, como as verificadas neste trabalho, especialmente em relação aos efeitos sobre a germinação de sementes,

Tabela 3 - Efeitos potencialmente alelopáticos de diferentes concentrações do extrato hidroalcoólico e do óleo essencial de folhas de cipó-d'alho (M. standleyi) sobre o desenvolvimento do hipocótilo de malícia (M. pudica). Dados expressos em percentual de inibição em relação ao tratamento testemunha (água destilada)

\begin{tabular}{|c|c|c|}
\hline \multirow{2}{*}{ Concentração (\%) } & \multicolumn{2}{|c|}{ Solução-teste } \\
\cline { 2 - 3 } & Extrato hidroalcoólico & Óleo essencial \\
\hline 0,5 & $11,5(0,85) \mathrm{Cb}$ & $18,4(1,10) \mathrm{Ca}$ \\
\hline 1,0 & $27,0(0,23) \mathrm{Bb}$ & $36,7(0,39) \mathrm{Ba}$ \\
\hline 2,0 & $33,2(0,72) \mathrm{Ab}$ & $51,2(0,38) \mathrm{Aa}$ \\
\hline
\end{tabular}

Médias seguidas de letras iguais, maiúsculas na coluna e minúsculas na linha, não diferem pelo teste de Tukey (5\%).

Planta Daninha, Viçosa-MG, v. 27, n. 4, p. 647-653, 2009 
podem ser indício da presença de compostos fenólicos, que são o maior grupo de compostos secundários das plantas e os mais frequentemente identificados como agentes alelopáticos (Mizutani, 1999; Xuan et al., 2003). Alguns compostos fenólicos são solúveis em água, o que justificaria sua presença em extratos hidroalcoólicos, como o deste trabalho.

A maior ou menor atividade alelopática de óleos essenciais também está associada às variações nos constituintes químicos. Por exemplo, Komai et al. (1991) indicaram que óleos essenciais que apresentavam maiores indices de inibição alelopática eram constituídos, principalmente, por sesquiterpenos que continham o grupo cetona ou hidroxila; os óleos constituídos de grupo acetato ou somente hidrocarboneto mostraram menor atividade alelopática. Weidenhamer et al. (1993) ressaltam, em seu trabalho, o poder fitotóxico dos monoterpenos e monoterpenos oxigenados como agentes alelopáticos. Os principais constituintes químicos identificados no óleo essencial do cipó-d'alho foram o dissulfeto de dialila $(42,15 \%)$ e o trissulfeto de dialila $(11,25 \%)$. Outros componentes sulfurados foram identificados no óleo de espécimes de $M$. standleyi cultivados no nordeste paraense (Zoghbi et al., 2008), como: sulfeto de dialila, dissulfeto de alilmetila, dissulfeto de alilpropila e trissulfeto de alilpropila. Não foram encontrados trabalhos com referência à atividade alelopática, individualmente ou em associação, para cada um desses componentes, o que indica nova propriedade biológica para estes.

Os resultados obtidos neste trabalho apontam para atividade alelopática do cipó-d'alho, com efeitos inibitórios efetivados pelo extrato hidroalcoólico (polar) e óleo essencial (apolar). Variações observadas nas intensidades dos efeitos estão associadas à concentração, à polaridade do extrato e aos parâmetros da planta receptora analisados. Essas condicionantes qualificam as folhas do cipó-d'alho como excelente fonte de compostos polares e apolares com atividade alelopática e, ao mesmo tempo, apontam para a necessidade de considerar, em estudos de prospecção de atividade alelopática, a utilização também de extratos apolares, especialmente se não houver informações disponiveis sobre a produção de óleo essencial pela planta. Nesse sentido, em estudo de prospecção de atividade alelopática em plantas, o uso de extratos apolares pode fornecer informações valiosas e complementares àquelas fornecidas pelo extrato polar, o que pode ajudar, substancialmente, na interpretação das informações relativas à atividade alelopática da planta em estudo, possibilitando melhor entendimento do papel representado por cada grupo de composto químico.

\section{LITERATURA CITADA}

ADAMS, R. P. Identification of essential oil components by gas chromatography/mass spectrometry. London: Allured Pub. Corp., 2007. 804 p.

AN, M; JOHNSON, I. R.; LOVETTE, J. V. Mathematical modeling of allelopathy: biological response to allelochemical and its interpretation. J. Chem. Ecol., v. 19, n. 10, p. $2379-2389,1993$

ANAYA, A. L. et al. Allelochemicals from Stauranthus perforatus, a Rutaceous tree of the Yucatan peninsula, Mexico. Phytochemistry, v. 66, n. 4, p. 487-494, 2005.

ANAYA, A. L. et al. Allelochemical potential of Callicarpa acuminata. J. Chem. Ecol., v. 29, n. 12, p. 2761-2776, 2003.

BARNEY, J. N. et al. Isolation and characterization of allelopathic volatiles from mugwort (Artemisia vulgaris). J. Chem. Ecol., v. 31, n. 2, p. 247-265, 2005.

CHON, S.U.; KIM, J.D. Biological activity and quantification of suspected allelochemicals from plant parts. J. Agron. Crop Sci., v. 188, n. 4, p. 281-285, 2002.

D'ABROSCA, B. et al. Structural charactezation of phytotoxic terpenoids from Cestrum parqui.

Phytochemistry, v. 66, n. 22, p. 2681-2688, 2005.

DIAS, A. P. C.; SOUZA FLLHO, A. P. S. Atividade potencialmente alelopática em extratos hidroalcoólicos de Cymbopogon sp. (Poaceae). R. Ci. Agrar., v. 44, n. 1, p. $37-48,2005$.

DUDAI, N. et al. Essential oils as allelochemicals and their potential use as bioerbicides. J. Chem. Ecol., v. 25, n. 5, p. $1079-1089,1999$

DUKE, O. S. et al. Chemical from nature for weed management. Weed Sci., v. 50, p. 138-151, 2002.

GATTI, A. B. et al. Atividade alelopática de extratos aquosos de Aristolochia esperanzae O. Kuntze na germinação e no crescimento de Lactuca sativa L. e Raphanus sativus L. Acta Bot. Bras., v. 18, n. 3, p. 459-472, 2004. 
HEISEY, R. M.; HEISEY, T. K. Herbicidal effects under field conditions of Ailanthus altissima bark extract, which contains ailanthone. Planta Soil, v. 256, n. 1, p. 85-90, 2003.

ISMAIL, B. S.; CHONG, T. V. Effects of equeous extracts and decomposition of Mikania micrantha H. B. K. debris on selected agronomic crops. Weed Biol. Manag., v. 2, n. 1, p. $31-38,2002$.

ISMAN, M. B. Plant essential oils for pest and disease management. Crop Protec., v. 19, n. 10, p. 603-608, 2000.

KATO-NOGUCHI, H. Isolation and identification of an allelopathic substance in Pisum sativum. Phytochemistry, v. 62 , n. 6, p. 1141-1144, 2003.

KHANH, T. D. et al. The exploitation of crop allelopathy in sustainable agricultural production. J. Agron. Crop Sci. v. 191, n. 3, p. 172-184, 2005

KOHLI, R. K.; SINGH, D. Allelopathic impact of volatile compounds from Eucalyptus on crop plants. Biol. Plant., v. 33 , n. 6 , p. $475-483,1991$

KOKKINI, S.;VOKOU, D. Mentha spicata (Lamiaceae) chemotypes growing wild in Greece. Econ. Bot., v. 43, n. 2, p. $192-202,1989$

KOMAI, K.; TANG, C. S.; NISHIMOTO, R. K. Chemotypes of Cyperus ritundus in Pacific Rim and inhibition of their essential oils. J. Chem. Ecol., v. 17, n. 1, p. 1-11, 1991.

KONG, C. et al. Volatile allelochemical in the Agerantum conyzoides intercropped citrus orchard and their effects on mites Amblyseus newsami and Panonychus citri. J. Chem. Ecol., v. 31, n. 9, p. 2193-2203, 2005

MIZUTANI, J. Secelected allelochemicals. Crit. Rev. Plant Sci., v. 18, n. 5, p. 653-671, 1999.

NISHIDA, N. et al. Allelopathic effects of volatile monoterpenoids produced by Salvia leucophylla: inhibition of cell proliferation and DNA synthesis in the root apical meristem of Brassica campestris seedlings. J. Chem. Ecol. v. 31, n. 5, p. 1187-1202, 2005.

RICE, E. L. Allelopathy. London: Academic Press, 1984 $413 \mathrm{p}$.
SAS Institute. User's guide. Version 6. 4.ed. Cary: 1989. $846 \mathrm{p}$.

SOBRERO, M. T.; OCHOA, M. C.; CHAILA, S. Potencial alelopático de Wedelia glauca: efeito sobre espécies hortícolas. Planta Daninha, v. 22, n. 1, p. 71-75, 2004.

SOUTO, X. C.; GONZÁLES, L.; REIGOSA, M. J. Allelopathy in forest environmental in Galícia, Spain. Allelopathy J., v. 2, n. 1, p. 67-78, 1995

SOUZA FILHO, A. P. S. Atividade potencialmente alelopática de extratos brutos e hidroalcoólicos de feijão-deporco (Canavalia ensiformis). Planta Daninha, v. 20, n. 3, p. $357-364,2002$.

SOUZA FILHO, A. P. S.; ALVES, S. M. Potencial alelopático de plantas de acapu (Vouacapoua americana): efeitos sobre plantas daninhas de pastagens. Planta Daninha, v. 18, n. 3, p. $435-441,2000$.

SOUZA FILHO, A. P. S.; DUTRA, S.; SILVA, M. A. M. M. Métodos de superação da dormência de sementes de plantas daninhas de pastagens cultivadas da Amazônia.

Planta Daninha, v. 16, n. 1, p. 3-11, 1998.

STOWE, L. G. Allelopathy and its influence on distribution of plants in Illinois old-field. J. Ecol., v. 67, n. 4, p. $1065-1085,1979$.

TARAYRE, $M$. et al. Intraspecific variation in the inhibition effects of Thymus vulgaris (Labiatae) monoterpenes on seed germination. Oecologia, v. 101, n. 1, p. 110-118, 1995

TURK, M. A.; SHATNAWI, M. K.; RAWAHA, A. M. Inhibitory effects of aqueous extracts of black mustard on germination and growth of alfafa. Weed Biol. Manag., v. 3, n. 1, p. $37-40,2003$

WEIDENHAMER, J. D. et al. Just how insoluble are monoterpenes? J. Chem. Ecol., v. 19, n. 8, p. 1799-1807, 1993.

XUAN, T. D. et al. Correlation between growth inhibitory exhibition and suspected allelochemicals (phenolic compounds) in the extract of alfafa (Medicago sativa L.) Plant Prod. Sci., v. 6, n. 3, p. 165-171, 2003

ZOGHBI, M. G. B. et al. Volatiles from Mansoa standleyi (Steyerm.) A. H. Gentry. J. Essential Oil Res. (Aceito para publicação, 2008) 